\title{
The efficacy and safety of the addition of poly ADP-ribose polymerase (PARP) inhibitors to therapy for ovarian cancer: a systematic review and meta-analysis
}

Yingzhu Yang ${ }^{1}$, Nannan $\mathrm{Du}^{2}$, Laidi Xie ${ }^{3}$, Jing Jiang ${ }^{1}$, Jiahang $\mathrm{Mo}^{2}$, Jiaze $\mathrm{Hong}^{2}$, Danyi $\mathrm{Mao}^{4}$, Derry Minyao $\mathrm{Ng}^{5}$ and Huiwei Shi ${ }^{1 *}$ (D)

\begin{abstract}
Background: The purpose of this study was to explore the efficacy and tolerability of poly ADP-ribose polymerase (PARP) inhibitors in patients with ovarian cancer.

Methods: The meta-analysis searched the PubMed, Web of Science, EBSCO, and Cochrane libraries from inception to February 2020 to identify relevant studies. And the main results of this study were long-term prognosis and treatment-related adverse events.

Results: The results showed that the addition of PARP inhibitors could significantly prolong progression-free survival (PFS) and overall survival (OS) for patients with ovarian cancer (HR 0.44, 95\% Cl 0.34-0.53, p<0.001; HR, 0.79 , 95\% Cl 0.65-0.94, $\mathrm{p}<0.001$, respectively). In the BRCA 1/2 mutation patients, the HR of PFS was 0.29 ( $p<$ $0.001)$, and the HR was $0.51(p<0.001)$ in the no BRCA $1 / 2$ mutation patients. The HR of PFS was $0.40(p<0.001)$ in the homologous recombination deficiency (HRD) mutation patients, while the HR was $0.80(p<0.001)$ in the no HRD mutation patients. Moreover, the analysis found that the use of PARP inhibitors did not significantly increase the risk of all grade adverse events (AEs) $(R R=1.04, p=0.16)$. But the incidence of grade 3 or higher AEs was increased ( $R R=1.87, p=0.002)$. In general, the AEs were mainly manifested in the blood system.

Conclusions: PARP inhibitors can improve the prognosis of ovarian cancer patients with and without genetic mutations (BRCA 1/2 or HRD). Furthermore, PARP inhibitors were tolerable to patients when added to their current therapy, although it inevitably adds the grade 3 and higher AEs.
\end{abstract}

Keywords: PARP inhibitor, Ovarian cancer, BRCA 1/2, HRD, Meta-analysis

\section{Background}

Ovarian cancer was the fourth most common cause of cancer-related deaths in women, with an estimated 200, 000 cases and 125,000 deaths worldwide each year [1]. More than two thirds of the patients were diagnosed as

\footnotetext{
* Correspondence: shihuiwei000@sina.com

'Department of Gynecology, Ningbo Women and Children's Hospital, Liuting Street 339, Haishu District, Ningbo, Zhejiang 315000, China

Full list of author information is available at the end of the article
}

advanced. Over $90 \%$ of malignant ovarian tumors were of epithelial origin and were called epithelial ovarian cancer. The most common and deadly epithelial ovarian cancer was high-grade serous ovarian cancer [2]. Moreover, the prognosis for the disease was poor: the 5-year survival rate standardized for the European average age was only $37.6 \%$ between 2000 and 2007 [3]. For the past decade, standard treatments for women with advanced ovarian cancer have been surgery and platinum-based

(c) The Author(s). 2020 Open Access This article is licensed under a Creative Commons Attribution 4.0 International License, which permits use, sharing, adaptation, distribution and reproduction in any medium or format, as long as you give appropriate credit to the original author(s) and the source, provide a link to the Creative Commons licence, and indicate if changes were made. The images or other third party material in this article are included in the article's Creative Commons licence, unless indicated otherwise in a credit line to the material. If material is not included in the article's Creative Commons licence and your intended use is not permitted by statutory regulation or exceeds the permitted use, you will need to obtain permission directly from the copyright holder. To view a copy of this licence, visit http://creativecommons.org/licenses/by/4.0/ The Creative Commons Public Domain Dedication waiver (http://creativecommons.org/publicdomain/zero/1.0/) applies to the data made available in this article, unless otherwise stated in a credit line to the data. 
chemotherapy. Some researchers have tried to improve this standard two-drug chemotherapy by adding a third cytotoxic drug, and the results have shown that it failed to affect progression-free survival or overall survival and resulted in increased toxicity [4-6]. In patients with newly diagnosed advanced ovarian cancer, the standard option was to add bevacizumab, an antiangiogenic agent, to carboplatin plus paclitaxel, and then bevacizumab alone $[7,8]$. However, the long-term efficacy of this medication was still uncertain.

On the other hand, studies have shown that PARP (poly ADP-ribose polymerase) was a key regulator of DNA damage repair, and PARP enzymes played a vital role in repairing single-strand breaks through base excision repair [9]. In double-strand break repair, PARP facilitated homologous repair and inhibited less conserved non-homologous and micro-homologous end-junction repair. Without PARP, homologous repair will not work and the less conservative repair process will dominate [10]. PARP inhibitors captured PARP on the DNA of the single-strand break site, thereby preventing the repair of these breaks and producing double-strand breaks, which were not accurate in tumors with homologous recombination deficiency (HRD) repair [11]. Recently, in some randomized clinical trials, the use of PARP inhibitors as a single drug or in combination with other drugs in patients with advanced ovarian cancer (including BRCA mutation or HRD mutation or neither mutation) can benefit this population to varying degrees [12-14]. Currently, some researchers have proposed four mechanisms for inhibiting PARP: (1) it inhibited PARP by inhibiting base excision repair. (2) It could capture PARP on damaged DNA [15], which interfered with the catalytic cycle of PARP, hindered DNA repair, and promoted double-strand breaks. (3) It could destroy the recruitment of BRCA1 to damaged DNA to achieve the effect of inhibiting PARP. (4) It could also activate nonhomologous end connections to inhibit PARP [16].

In addition, studies have shown that PARP inhibitors can prevent cancer cells from repairing damaged DNA and leading to cancer cell death [17]. Its role was to capture the repair complex at the site of single-strand breaks, preventing replication and causing further damage [18]. In fact, the DNA damage induced by PARP inhibitors affected the process of mitosis. The detailed mechanism was that PARP inhibitors will damage the stability of the replication fork and cause DNA damage, which will be transferred to mitosis. During mitosis, these DNA damages could lead to chromatin bridges and lead to cytokinesis failure, multinucleation, and cell death. Other studies have shown that PARP inhibitors could promote the induction of cell death through the process of mitosis and eliminate the cytotoxicity caused by PARP inhibitors in some ways [19]. However, for patients with BRCA 1/2 unmutated and HRD unmutated, the efficacy of PARP inhibitors was still uncertain. The purpose of this study was to explore the efficacy and tolerability of PARP inhibitors in patients with ovarian cancer.

\section{Methods}

\section{Search strategy}

The meta-analysis searched the PubMed, Web of Science, EBSCO, and Cochrane libraries from the beginning to February 2020 to identify relevant studies. Because the authors have different calling habits for the same drug in the literatures, we choose a combination of freetext terms and medical subject heading terms which was used for topic search to ensure the integrity of the included literatures. Search terms included "PARP inhibitor," "poly ADP-ribose polymerase inhibitor," "olaparib," "rucaparib," "veliparib," "niraparib," "talazoparib," “iniparib," "ovarian neoplasms," "ovarian cancer," "ovarian carcinoma," "carcinoma of ovary," or "ovary cancer." Also, we manually search for references in the literature. In order to make the study more standardized and its conclusions more scientific, this meta-analysis was conducted following the guidelines of the Preferred Reporting Items for Systematic Review and Meta-Analysis Protocols (PRISMA-P) 2015 statement [20].

\section{Inclusion and exclusion criteria}

Inclusion criteria: (1) included articles were English reports of completed clinical controlled trials evaluating the efficacy of PARP inhibitors to ensure the completeness of included studies. (2) The included articles were randomized controlled trials (RCTs) for PARP inhibitors in phase II and phase III for patients with ovarian cancer in order to increase the credibility of the research conclusion. (3) Included articles mentioned PFS (progression-free survival) and/or OS (overall survival) so that we could effectively analyze the results.

Exclusion criteria: (1) research treatments that included neoadjuvant therapy. (2) The trial was not a phase II or phase III clinical trial. (3) Research data cannot be extracted. (4) In the event where the author has repeated publications or continuous updates, we would use the latest article.

\section{Outcome measures}

The main results of this study were long-term prognosis (including PFS and OS) and treatment-related adverse events (AEs), because these two types of indicators played a vital role in the prognosis of patients.

The incidence of AEs was characterized based on all grades and grade 3 or higher as reported by each trial using the definitions of National Cancer Institute's 
Common Terminology Criteria for Adverse Events (CTCAE) version 4. 0[21].

\section{Assessment of the risks of bias and data extraction}

We assessed the potential risks of bias in trials by using the Cochrane Collaboration Risk of Bias Assessment tool [22]. In order to ensure the objectivity and accuracy of the entered data, two investigators completed the review independently. A third investigator resolved disagreements. The basic information of each study was independently extracted by two researchers. The baseline information included author, publication period, the number of ClinicalTrials.gov, the phase of clinical trials, the regimen of the experimental group of using a PARP inhibitor and control group, the number of participants, tumor mutation, first-line or non-first-line treatment, and survival benefit indicators including PFS, OS, and AEs. If different studies contain different chemotherapy regimens, we can try to conduct a subgroup analysis when the sample size is sufficient. However, if the chemotherapy regimens are variable and the samples are insufficient, we carefully combine the corresponding results.

\section{Statistical analysis}

We compared the PFS and OS of the experimental group of using a PARP inhibitor and the control group, expressed as hazard ratio (HR) and 95\% confidence interval (CI), and the AEs involved were also expressed as risk ratio (RR) and $95 \%$ CI. All pooled results are displayed using the forest plots. We used Begg's and Egger's test with a level of significance set at $P<0.1$ to evaluate publication bias and the Stata 12.0 Software to perform the sensitivity bias [23]. Because this study included a variety of treatments, we used a random-effects model in order to increase credibility. $\mathrm{P}$ value less than 0.05 was considered statistically significant.

\section{Results}

\section{Eligible studies and inclusion features}

After rigorous searching and selection, including manual searching, we have identified 1247 potentially relevant articles. In the excluding neoadjuvant therapy, not a PARP inhibitor compared to other, non-phase II or III studies and data unavailable after, the study included ten related articles ultimately [12-14, 24-30]. The minute search and selection process are detailed in Supplementary Figure 1. These included studies involving three clinical phase II trials and seven clinical phase III trials, which covered a total of 5006 patients. Of which, PARP inhibitors were used as a non-first-line treatment in six studies and as first-line treatment in four studies. In the choice of treatment therapy, six studies chose the treatment regimen of PARP inhibitors versus placebo. Four experimental groups of studies treated with PARP inhibitors in combination with other drugs. In the selection of PARP inhibitors, most studies (6) chose olaparib. Among these objects of study, three studies incorporated the population of BRCA 1/2 mutation. At the end of the study results, all studies reported PFS and five studies reported OS. Detailed research characteristics are shown in Supplementary Table 1.

\section{Efficacy of PARP inhibitors on the PFS and OS}

In this included study, all of them reported on PFS, which the results showed that the use of PARP inhibitors could significantly prolong PFS (HR 0.44, 95\% CI 0.34-0.53, p < 0.001; Fig. 1). Besides, we performed a subgroup analysis of the included population, which had a genetic mutation or not. The analysis found the classification method of two gene mutations in the included population, in which one was the BRCA $1 / 2$ mutation and the other was the HRD mutation. In the BRCA $1 / 2$ mutation patients, the HR of PFS was 0.29 (95\% CI $0.24-0.34, p<0.001$; Fig. 2$)$, and the HR was 0.51 (95\% CI $0.42-0.61, p<0.001$; Fig. 2) in the no BRCA $1 / 2$ mutation patients. The HR of PFS was $0.40(95 \%$ CI $0.32-0.48, p<0.001$; Fig. 3) in the HRD mutation patients, while the HR was 0.80 (95\% CI 0.66-0.94, $p<$ 0.001; Fig. 3) in the no HRD mutation patients. Studies have shown that the PFS of people with BRCA $1 / 2 \mathrm{mu}-$ tation or HRD mutation was significantly longer than no gene mutation.

In this study cohort, there were a total of five studies that mentioned OS. Estimates of HR and at $95 \%$ CI were weighted and pooled using the random effect model. The results showed that the experimental groups using PARP inhibitors could significantly prolong OS compared with the control group (HR 0.79, 95\% CI 0.650.94, $p<0.001$; Fig. 4). Also, the heterogeneity was low.

\section{Analysis of the adverse events of PARP inhibitors}

The analysis found that the use of PARP inhibitors did not significantly increase the overall risk of AEs $(\mathrm{RR}=$ 1.04, $\mathrm{p}=0.16$ ). Anemia and thrombocytopenia were the most common AEs, with risk values of 3.40 (95\% CI $1.86-6.19, p<0.001$ ) for anemia and 3.59 (95\% CI 1.65$7.78, p<0.001)$ for thrombocytopenia. The other AEs were different such as decreased appetite $(R R=1.45)$, diarrhea $(R R=1.23)$, dizziness $(R R=1.46)$, fatigue $(R R$ $=1.36)$, headache $(R R=1.35)$, nausea $(R R=1.71)$, neutropenia $(R R=1.88)$, and vomiting $(R R=1.82)$. Among grade 3 and higher AEs, the overall risk increased $(\mathrm{RR}=$ 1.87, $p=0.002$ ). Among the various AEs, anemia and thrombocytopenia were the more significant increase, and their risk values were 9.94 (95\% CI 2.63-37.50, $p<$ 0.001 ) for anemia and 4.46 (95\% CI 1.26-17.19, $p=$ $0.02)$ for thrombocytopenia. The other AEs were fatigue 


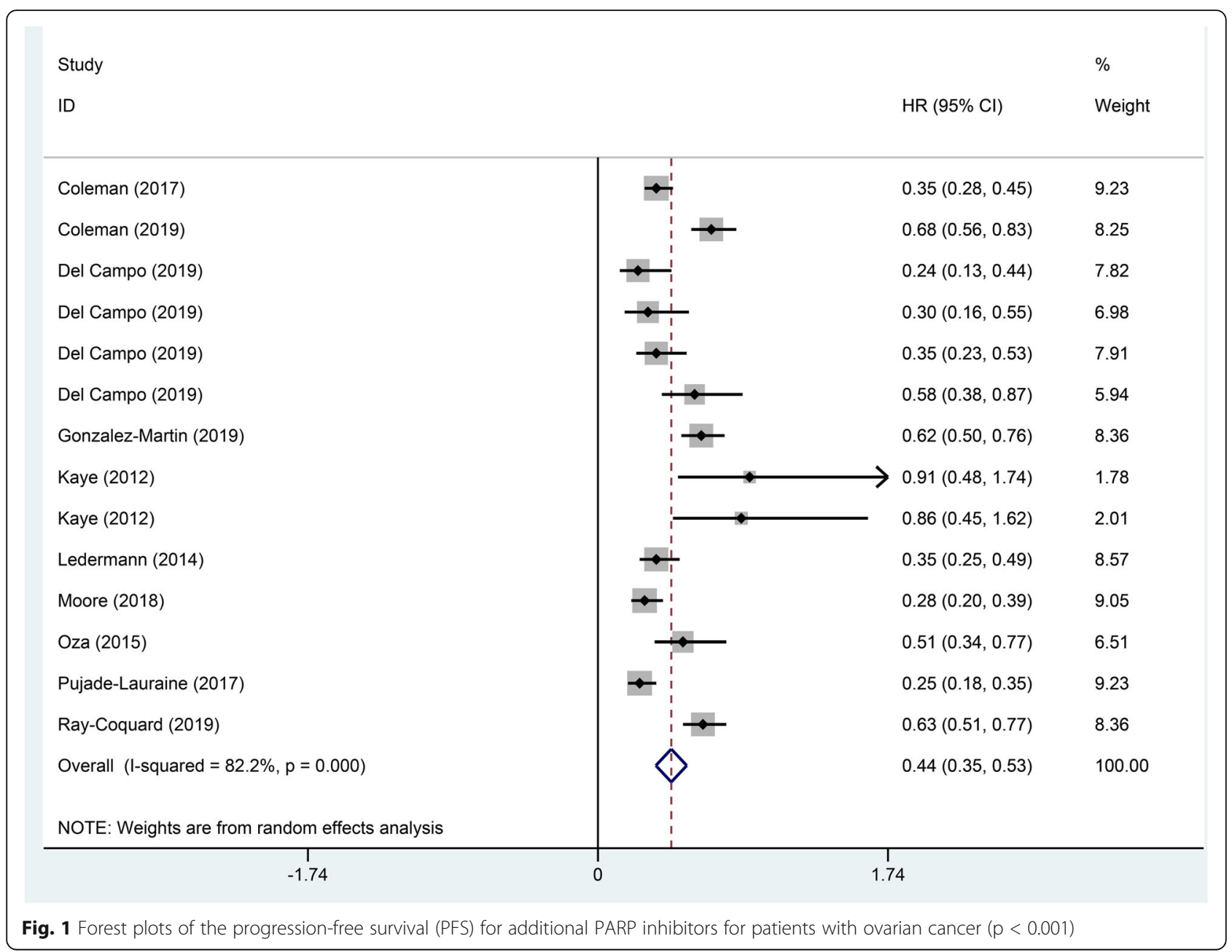

$(\mathrm{RR}=2.39)$, nausea $(\mathrm{RR}=2.57)$, and neutropenia $(\mathrm{RR}=$ 2.42). In general, the AEs were mainly manifested in the blood system. Detailed data are shown in Tables 1 and 2 .

\section{Publication bias and sensitivity analysis of PFS}

Due to the more considerable heterogeneity of PFS $\left(\mathrm{I}^{2}=\right.$ $82.2 \%$ ), we performed a publication bias test on the relationship between PFS and PARP inhibitors, which was no significant publication bias (Egger's $\mathrm{p}=0.241$, Begg's $\mathrm{p}=1.00$ ). Through the sensitivity analysis of PFS, it was found that removing each group showed excellent stability in turn (Supplementary Fig. 2 and Supplementary Fig. 3).

\section{Discussion}

PARP inhibitors were originally developed as a radiosensitizer and chemical sensitizer for cancer treatment, but Mateo et al. pointed out in the article that some preclinical observations support the development of PARP inhibitors as a single drug for BRCA 1/2-deficient cancer [31]. Most data on BRCA $1 / 2$ in 2005 related to the role of these genes as risk susceptibility factors for familial breast and ovarian cancer [32]. In light of this, carriers of germline BRCA 1/2 (gBRCA 1/2) mutation were the initial target population to test the PARPi (PARP inhibitors)-BRCA synthetic lethal hypothesis in the clinic [33, 34]. Since its initial approval, several other clinical trials have determined the clinical activity of PARP inhibitors in a subset of patients with somatic BRCA $1 / 2$ mutation or another defect in the homologous recombination pathway $[28,35,36]$. With the deepening of research, it has been discovered that PARP inhibitors were not only beneficial for patients with ovarian cancer with mutation in BRCA $1 / 2$ and HRD, but also for patients with no mutation possibly in ovarian cancer [10]. Based on this, we conducted a systematic meta-analysis to assess whether PARP inhibitors would benefit all patients with ovarian cancer (including a mutation in the BRCA $1 / 2$ or HRD, or neither).

The results of this meta-analysis study showed that the addition of PARP inhibitors to patients with platinumsensitive ovarian cancer had a benefit in long-term prognosis. González-Martin et al. [30] and Kaye et al. [24] have come up with conclusions consistent with our 
a

Study

ID

$\%$

$\mathrm{HR}(95 \% \mathrm{Cl})$

Weight

\begin{tabular}{lll}
\hline Coleman (2017) & $0.20(0.13,0.32)$ & 13.37 \\
Coleman (2019) & $0.44(0.28,0.68)$ & 4.90 \\
Del Campo (2019) & $0.24(0.13,0.44)$ & 7.28 \\
Del Campo (2019) & $0.30(0.16,0.55)$ & 5.19 \\
Gonzalez-Martin (2019) & $0.40(0.27,0.62)$ & 6.07 \\
Ledermann (2014) & $0.22(0.12,0.40)$ & 8.41 \\
Oza (2015) & $0.21(0.08,0.55)$ & 3.74 \\
Ray-Coquard (2019) & $0.31(0.20,0.47)$ & 8.84 \\
Ray-Coquard (2019) & $0.33(0.25,0.45)$ & 12.68 \\
Kaye (2012) & $0.91(0.48,1.74)$ & 0.59 \\
Kaye (2012) & $0.86(0.45,1.62)$ & 0.68 \\
Pujade-Lauraine (2017) & $0.25(0.18,0.35)$ & 14.87 \\
Moore (2018) & $0.28(0.20,0.39)$ & 13.37 \\
Overall (I-squared =31.7\%, $\mathrm{p}=0.129)$ & $0.29(0.24,0.34)$ & 100.00 \\
NOTE: Weights are from random effects analysis & & \\
\hline
\end{tabular}

$\mathrm{b}$

Study

HR $(95 \% \mathrm{Cl}) \quad$ Weight

ID

Coleman (2017)

Coleman (2017)

Del Campo (2019)

Del Campo (2019)

Gonzalez-Martin (2019)

Ledermann (2014)

Ray-Coquard (2019)

Ray-Coquard (2019)

Overall (1-squared $=46.6 \%, p=0.069$ )

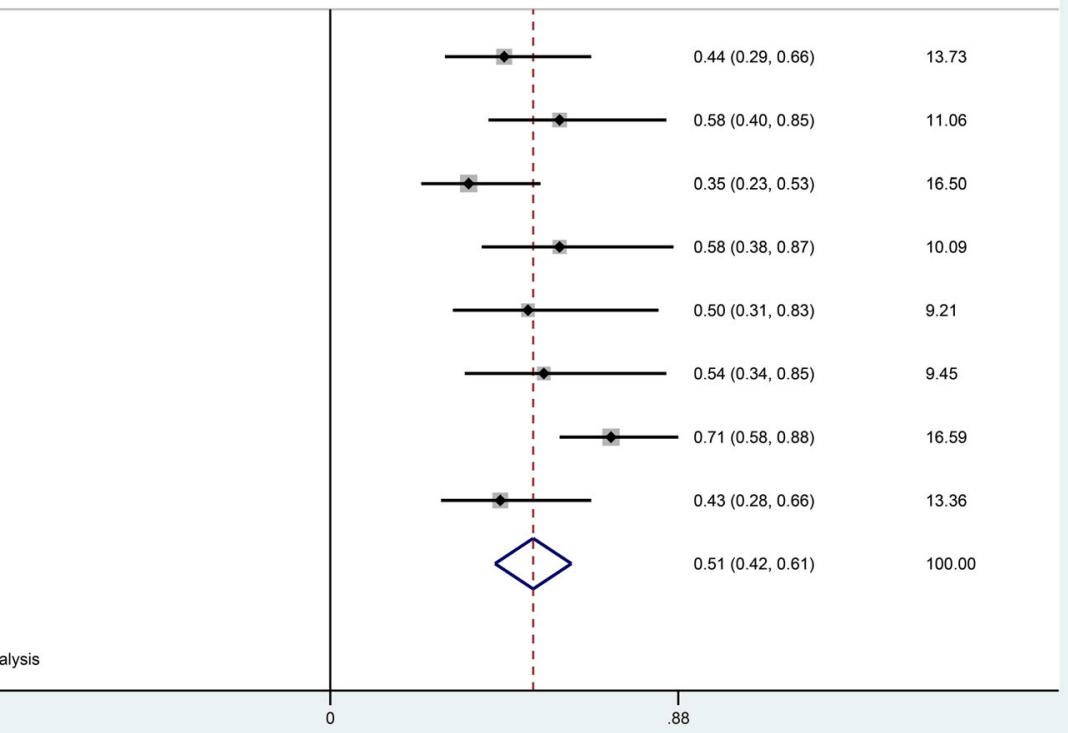

Fig. 2 Forest plots of the progression-free survival (PFS) for additional PARP inhibitors. a BRCA $1 / 2$ mutation $(p<0.001)$. b no BRCA $1 / 2$ mutation $(p<0.001)$ 
a

Study

$\mathrm{HR}(95 \% \mathrm{Cl})$

$\%$

ID

Weight

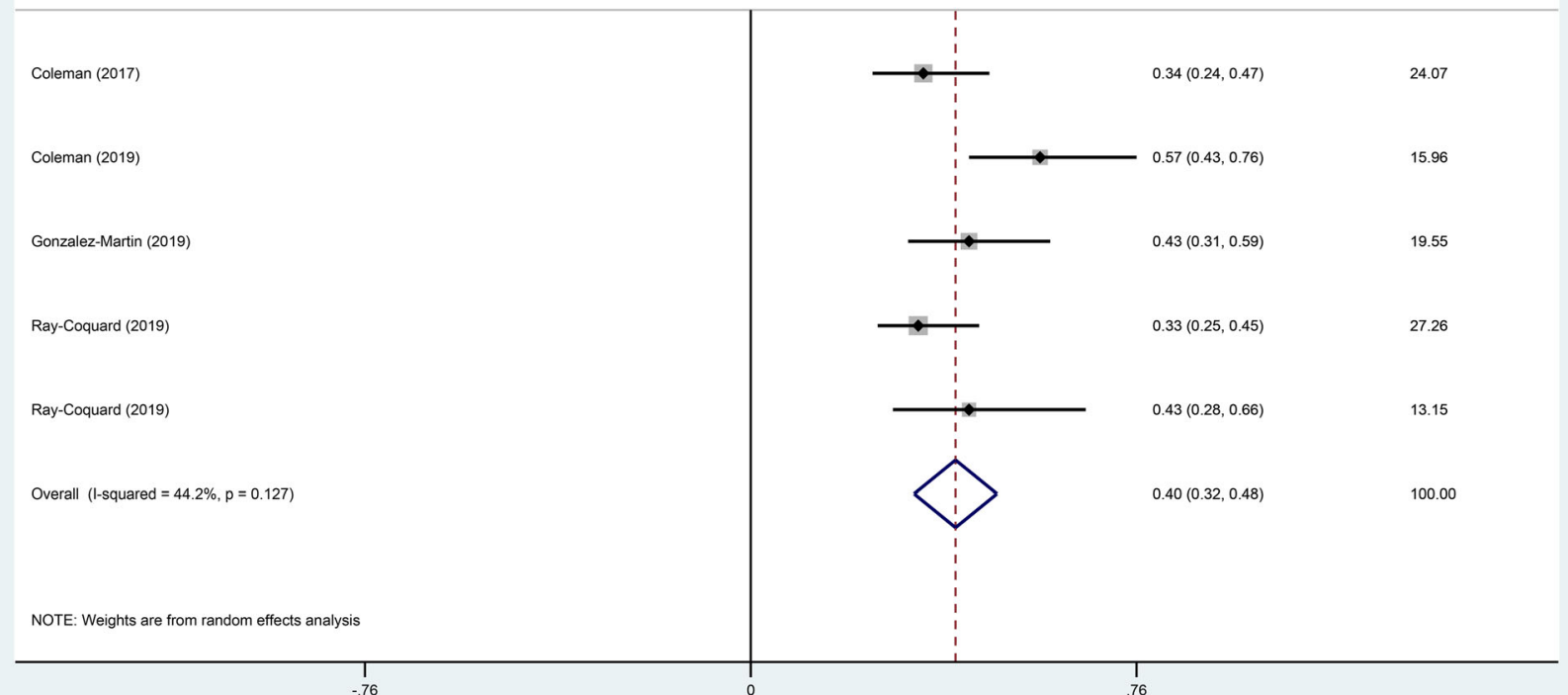

b

Study

$\%$

10

$\mathrm{HR}(95 \% \mathrm{Cl})$

Weight

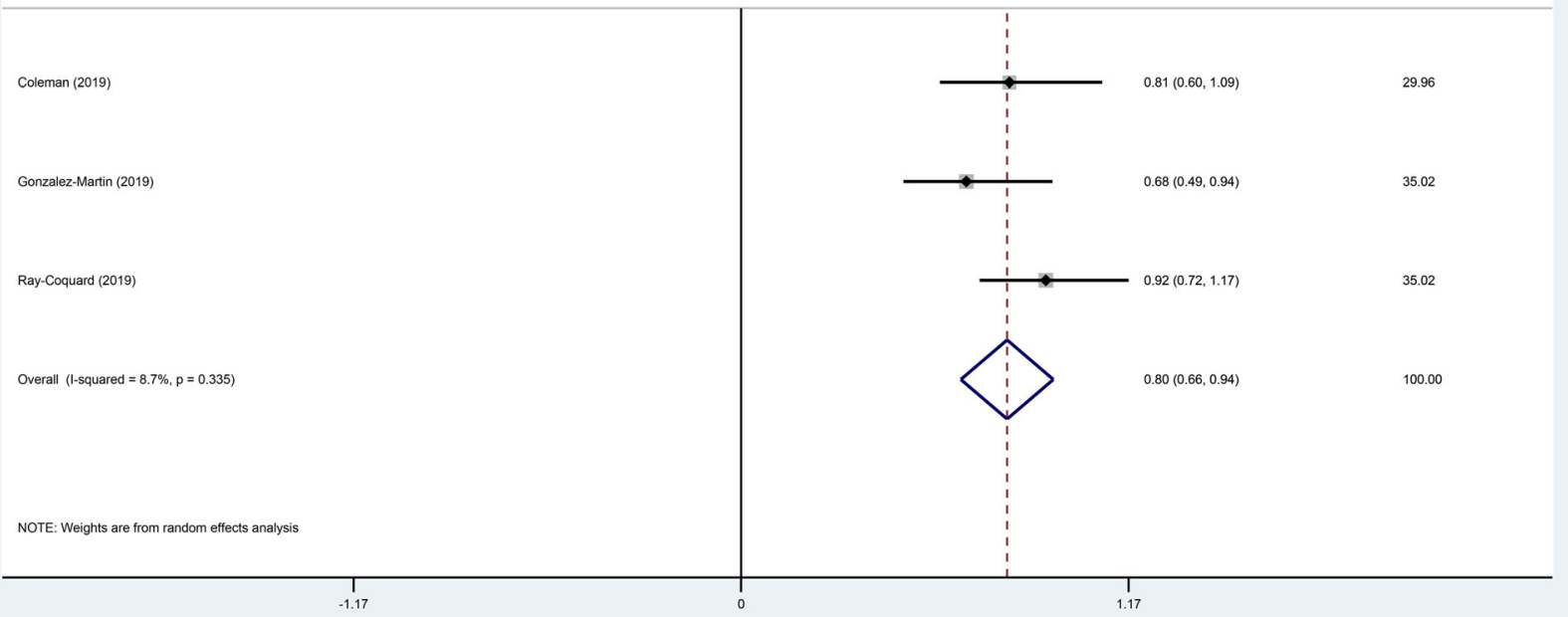

Fig. 3 Forest plots of the progression-free survival (PFS) for additional PARP inhibitors. a HRD mutation $(p<0.001)$. $\mathbf{b}$ no HRD mutation ( $p<0.001)$ 


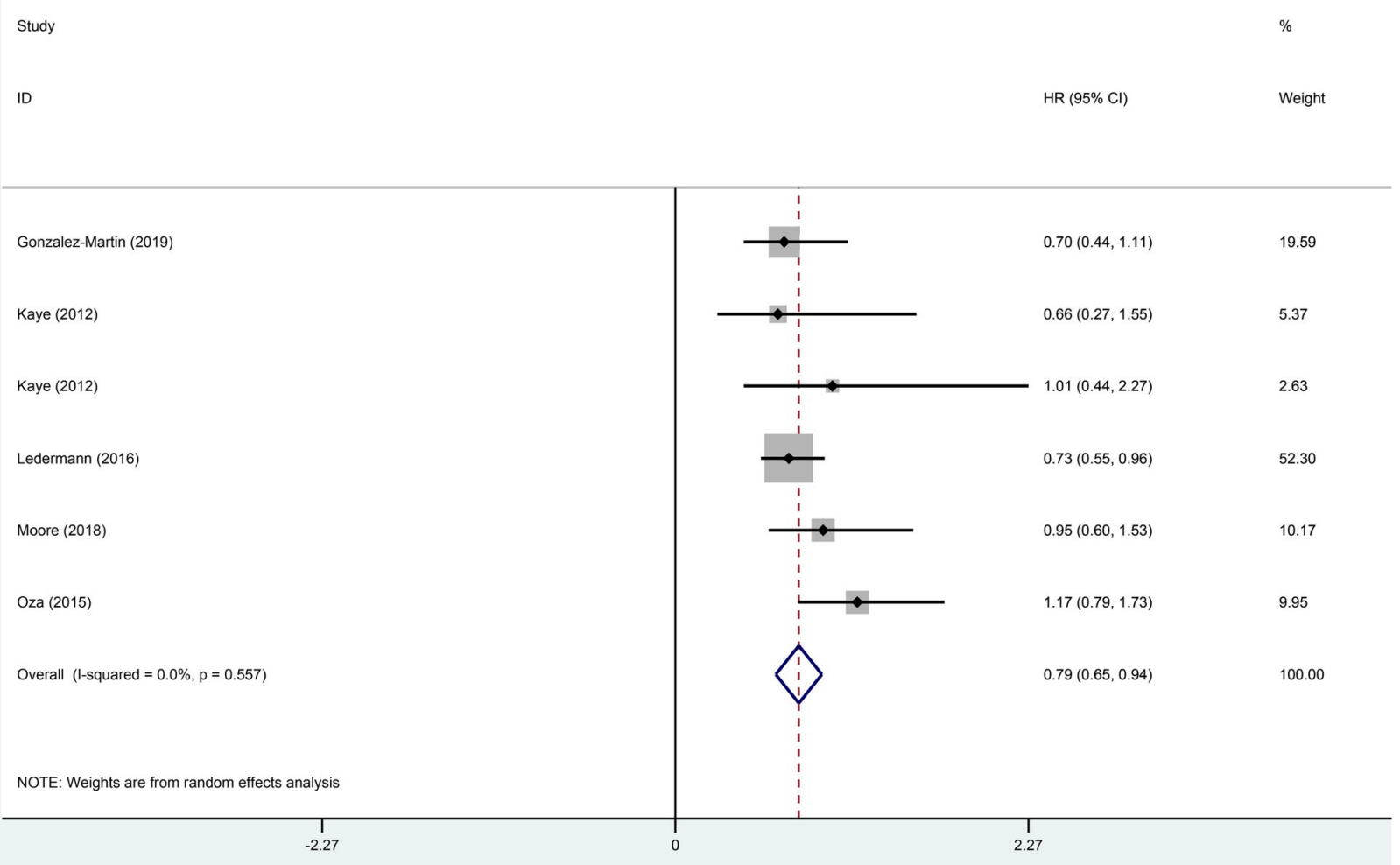

Fig. 4 Forest plot of the overall survival (OS) for additional PARP inhibitors for patients with ovarian cancer $(p<0.001)$

research through randomized clinical trials. Besides, the addition of PARP inhibitors had a greater benefit for ovarian cancer patients with BRCA $1 / 2$ mutation and HRD mutation, especially for ovarian cancers with BRCA $1 / 2$ mutation. This may be related to the fact that PARP inhibitors prevent the growth of cancer cells by inducing synthetic lethality with defects in DNA repair (such as BRCA 1/2 mutant cells) [37]. In terms of the AEs of the PARP inhibitors, the main AEs of the addition to PARP inhibitors were reflected in the blood system. Studies have shown [36] that hematological toxicity was a very common concomitant effect of PARP inhibitors, but these AEs tended to occur early after treatment begins and recover after a few months, so its overall effect was safe and tolerable.

For patients with ovarian cancer, from long-term prognosis, the addition of PARP inhibitors can benefit patients with ovarian cancer and prolong the overall disease control survival rate [14]. From the perspective of the mechanism of action of PARP inhibitors, it was found that the PARP inhibitors specifically hinder DNA repair. Therefore, we performed a subgroup analysis on whether the ovarian cancer patients had a genetic mutation and its mutation type. The analysis showed that regardless of whether the ovarian cancer patients were genetically mutated or not (BRCA $1 / 2$ mutation or HRD mutation), the addition of PARP inhibitors could extend the prognosis of this population, and that those with BRCA $1 / 2$ mutation or HRD mutation had significantly longer prognosis than no gene mutation. Ledermann et al. [38] and Majdak et al. [39] also reached the same conclusions as us. Studies have shown that PARP inhibitors significantly impaired the survival rate of cells with a homozygous mutation in the BRCA $1 / 2$ gene [40, 32]. At the same time, some researchers have pointed out that cells with defective BRCA proteins cannot repair double-stranded DNA breaks through homologous recombination and rely on other approaches to repair DNA damage, especially detecting single DNA strand breaks and activating multiple effector proteins to initiate promoter repair of the PARP pathway [41], while PARP enzymes played a key role in the repair of singlestrand breaks repaired by base excision [9], and inhibition of PARP in the presence of HRD leads to cells' death because the process was called "synthetic lethality" [42], which led to an overall genetic disorder.

Most interestingly, in the absence of BRCA1/2 mutation or HRD mutation, PARP inhibitors also had clinical benefits $[43,37]$. This phenomenon suggested that the role of PARP-1 in DNA damage repair may not be the sole reason for its therapeutic potential [44]. Boamah et al. [45] pointed out in the study that PARP-1 was 
Table 1 Subgroup analysis of the any grade adverse events

\begin{tabular}{|c|c|c|c|c|c|}
\hline Experimental vs. control & $\begin{array}{l}\text { No. of } \\
\text { studies }\end{array}$ & $R R$ & $95 \% \mathrm{Cl}$ & $p$ & $\begin{array}{l}\text { Heterogeneity } \\
\left(1^{2}\right)(\%)\end{array}$ \\
\hline Any grade adverse events & 8 & 1.04 & $0.99-1.10$ & 0.16 & 97 \\
\hline Any grade abdominal pain & 9 & 0.97 & $0.84-1.12$ & 0.68 & 36 \\
\hline Any grade anemia & 9 & 3.40 & $1.86-6.19$ & $<0.001$ & 95 \\
\hline Any grade arthralgia & 7 & 0.94 & $0.82-1.07$ & 0.32 & 0 \\
\hline Any grade constipation & 9 & 1.16 & $0.91-1.49$ & 0.22 & 75 \\
\hline Any grade decreased appetite & 6 & 1.45 & $1.21-1.74$ & $<0.001$ & 7 \\
\hline Any grade diarrhea & 8 & 1.23 & $1.07-1.40$ & 0.003 & 20 \\
\hline Any grade dizziness & 6 & 1.46 & $1.11-1.94$ & 0.008 & 36 \\
\hline Any grade fatigue & 9 & 1.36 & $1.20-1.53$ & $<0.001$ & 65 \\
\hline Any grade headache & 8 & 1.35 & $1.04-1.74$ & 0.02 & 68 \\
\hline Any grade nausea & 9 & 1.71 & $1.35-2.17$ & $<0.001$ & 92 \\
\hline Any grade neutropenia & 8 & 1.88 & $1.23-2.87$ & 0.003 & 89 \\
\hline Any grade thrombocytopenia & 7 & 3.59 & $1.65-7.78$ & 0.001 & 91 \\
\hline Any grade vomiting & 9 & 1.82 & $1.48-2.23$ & $<0.001$ & 60 \\
\hline
\end{tabular}

involved in ribosome biogenesis through its enrichment in nucleoli and ADP ribosylation of several nucleolar proteins. In addition, studies have shown that PARP-1 binds to non-coding promoter-related RNA, which helps to establish silent rDNA chromatin and inhibit rRNA transcription [46]. Therefore, there were speculations that PARP inhibitors may benefit patients with ovarian cancer without a genetic mutation (BRCA1/2 mutation or HRD mutation) for two reasons [37]: (1) the role of PARP-1-RNA interactions in the nucleoli and (2) the role of PARP-1 in site-specific modification of protein substrates in ribosome biogenesis. The above reasons may explain that PARP inhibitors can also benefit patients with ovarian cancer who are not genetically mutated (BRCA1/2 mutation or HRD mutation). However, the mechanism of action of PARP inhibitors needs further study.

In terms of AEs, the use of PARP inhibitors did not significantly increase the overall risk of AEs $(\mathrm{RR}=1.04, p=$ 0.16), but in specific AEs, anemia and thrombocytopenia were the most common AEs, and their risk values were 3.40 (95\% CI 1.86-6.19, $p<0.001$ ) for anemia and 3.59 (95\% CI 1.65-7.78, p < 0.001) for thrombocytopenia. Other AEs included decreased appetite $(R R=1.45)$,

Table 2 Subgroup analysis of the grade 3 or higher adverse events

\begin{tabular}{|c|c|c|c|c|c|}
\hline Experimental vs. control & $\begin{array}{l}\text { No. of } \\
\text { studies }\end{array}$ & $\mathrm{RR}$ & $95 \% \mathrm{Cl}$ & $\mathrm{p}$ & $\begin{array}{l}\text { Heterogeneity } \\
\left(I^{2}\right)(\%)\end{array}$ \\
\hline Grade 3 or higher adverse events & 8 & 1.87 & $1.27-2.77$ & 0.002 & 96 \\
\hline Grade 3 or higher abdominal pain & 9 & 1.08 & $0.69-1.68$ & 0.74 & 0 \\
\hline Grade 3 or higher anemia & 10 & 9.94 & $2.63-37.50$ & $<0.001$ & 92 \\
\hline Grade 3 or higher arthralgia & 7 & 0.81 & $0.32-2.03$ & 0.66 & 0 \\
\hline Grade 3 or higher constipation & 9 & 0.92 & $0.31-2.72$ & 0.88 & 16 \\
\hline Grade 3 or higher decreased appetite & 6 & 2.39 & $0.76-7.52$ & 0.14 & 0 \\
\hline Grade 3 or higher diarrhea & 8 & 0.92 & $0.53-1.59$ & 0.75 & 0 \\
\hline Grade 3 or higher dizziness & 6 & 0.85 & $0.12-5.99$ & 0.87 & 36 \\
\hline Grade 3 or higher fatigue & 10 & 2.39 & $1.67-3.44$ & $<0.001$ & 0 \\
\hline Grade 3 or higher headache & 8 & 0.55 & $0.22-1.37$ & 0.20 & 0 \\
\hline Grade 3 or higher nausea & 9 & 2.57 & $1.57-4.22$ & $<0.001$ & 0 \\
\hline Grade 3 or higher neutropenia & 9 & 2.42 & $1.41-4.17$ & 0.001 & 81 \\
\hline Grade 3 or higher thrombocytopenia & 8 & 4.66 & $1.26-17.19$ & 0.02 & 84 \\
\hline Grade 3 or higher vomiting & 9 & 1.43 & $0.86-2.37$ & 0.17 & 0 \\
\hline
\end{tabular}


diarrhea $(R R=1.23)$, and dizziness $(R R=1.46)$. Among grade 3 and higher AEs, the overall risk of AEs increased $(\mathrm{RR}=1.87, \mathrm{p}=0.002)$. Among the various AEs, the more significant increase was anemia and thrombocytopenia, and their risk values were 9.94 (95\% CI 2.63-37.50, p < $0.001)$ and 4.46 (95\% CI 1.26-17.19, $\mathrm{p}=0.02)$, respectively. Other AEs were fatigue $(R R=2.39)$, nausea $(R R=$ 2.57 ), and neutropenia $(R R=2.42)$. Overall, its AEs were mainly manifested in the blood system. Such AEs tended to occur early after the start of treatment and recovered after a few months. Among patients receiving niraparib, hematological of AEs accounted for the majority of grade 3 and grade 4, which were the most common cause of dose adjustment, interruption, and discontinuation [35]. Studies by Swisher et al. [36] indicated that anemia was the most common hematological toxicity among PARP inhibitors. Anemia may be a one of the targeted AEs related to PARP2 inhibition and erythropoiesis. In addition, Farrés et al. [47] pointed out that when the plasma concentration of erythropoietin increases, the loss of PARP2 can impair the differentiation of red blood cell-like progenitor cells and reduce the life span of red blood cells. We speculated that anemia, one of the toxicities of PARP inhibitors in the blood system, may be related to the above mechanism, but its mechanism had not yet been clarified and needed further study.

Regarding the AEs of thrombocytopenia, a study published by Berek et al. [48] in 2018 pointed out that patients with a baseline weight of less than $77 \mathrm{~kg}$ or a platelet count of less than 150,000 cells $/ \mathrm{mL}$ had a baseline level above, and patients had more grade 3 or more thrombocytopenia events in the first month $(35 \%$ vs $12 \%)$. In the case of PARP inhibitors, the cause of thrombocytopenia was associated with a reversible reduction in megakaryocyte proliferation and maturation [48]. However, thrombocytopenia usually occurred during the first month of treatment in general [36]. At the same time, FDA recommended that patients starting PARP inhibitors be tested weekly to monitor platelet concentration during the first month. In addition, neutropenia was the third most common hematological toxicity observed [36]. Although full grade neutropenia was observed in 18 to $30 \%$ of patients, niraparib (72 of 367 patients [20\%]) and rucaparib (25 of 372 patients [7\%]) had higher grade 3 and 4 AEs (10 of 195 patients [5\%]) $[28,35,27]$.

Although these grade 3 and higher AEs were relatively serious, fortunately, Oza et al. [49] reported quality of life data for patients who received niraparib as maintenance therapy; they pointed out that with the exception of nausea, all reported symptoms improved or remained stable during treatment of niraparib. At the same time, a study of quality of life on olaparib [50] eliminated the effects of AEs in the treatment and placebo groups through a unique analysis of quality-adjusted progression-free survival, which objectively significantly reduced people's concerns about the toxic effects of PARP inhibitors. The above conclusions indicated that the AEs of PARP inhibitors were tolerable, and their duration was short [51], which would not have a serious impact on the prognosis of patients. However, these phenomena, including their mechanism of action, were not clear at present, and further research on PARP inhibitors was needed.

\section{Strengths and limitations}

This was a meta-analysis to analyze that PARP inhibitors were associated with the prognosis of patients with ovarian cancer and AEs systematically and comprehensively. In addition, all the studies included in this meta-analysis were RCTs of phase II and phase III. However, this study showed that the sample size was insufficient and the different treatment schemes included in the study led to the diversification of the overall treatment plan of the article, which reduced the credibility of the conclusions drawn by the article. Even if we used the random effect model to increase the credibility of the conclusion as much as possible, the conclusions obtained in this article still needed to be proved by further clinical experiments.

\section{Conclusion}

PARP inhibitors can not only prolong the prognosis of ovarian cancer patients with genetic mutation (BRCA 1/ 2 mutation or HRD mutation), but also prolong the prognosis of ovarian cancer patients of no gene mutation. Furthermore, PARP inhibitors were tolerable to patients when added to their current therapy, although it inevitably adds the grade 3 and higher AEs.

\section{Supplementary information}

Supplementary information accompanies this paper at https://doi.org/10. 1186/s12957-020-01931-7.

Additional file 1: Supplementary Fig. 1. Flow diagram of study inclusion and exclusion.

Additional file 2: Supplementary Fig. 2. Publication bias of the progression-free survival (PFS) for additional PARP inhibitors. (Egger's) $p=$ 0.241; (Begg's) $p=1.0$.

Additional file 3: Supplementary Fig. 3. Sensitivity analysis of the progression-free survival (PFS) for additional PARP inhibitors.

Additional file 4: Supplementary Table 1. Characteristics of included clinical trials in the meta-analysis.

\section{Abbreviations}

PARP: Poly ADP-ribose polymerase; HRD: Homologous recombination deficiency; PFS: Progression-free survival; OS: Overall survival; AEs: Adverse events; RCTs: Randomized controlled trials; HR: Hazard ratio; RR: Risk ratio; 95\% Cl: Confidence interval of 95\% 


\section{Acknowledgements}

None.

\section{Authors' contributions}

HWS designed the research process. YZY, NND, and LDX searched the database for corresponding articles. JJ and JHM extracted useful information from the articles above. JZH and DYM used statistical software for analysis. DMN drafted the meta-analysis. HWS polished this article. All authors had read and approved the manuscript and ensured that this was the case.

\section{Funding}

Funding was provided by the Medical Health Science and Technology Project of Zhejiang Provincial Health Commission (2018KY716).

\section{Availability of data and materials}

All the data and material are available.

\section{Ethics approval and consent to participate}

This article does not contain any studies with human or animal subjects performed by any of the authors.

\section{Consent for publication}

Approved.

\section{Competing interests}

The authors declare that they have no conflict of interest.

\section{Author details}

'Department of Gynecology, Ningbo Women and Children's Hospital, Liuting Street 339, Haishu District, Ningbo, Zhejiang 315000, China. ${ }^{2}$ The Second Clinical Medical College, Zhejiang Chinese Medical University, Hangzhou, Zhejiang, China. ${ }^{3}$ Zhejiang University, School of Medicine, Hangzhou, Zhejiang, China. ${ }^{4}$ Basic Medical College, Zhejiang Chinese Medical University, Hangzhou, Zhejiang, China. ${ }^{5}$ Medical College of Ningbo University, Ningbo, Zhejiang, China.

\section{Received: 6 May 2020 Accepted: 23 June 2020}

\section{Published online: 04 July 2020}

\section{References}

1. Bookman MA, Brady MF, McGuire WP, Harper PG, Alberts DS, Friedlander M, Colombo N, Fowler JM, Argenta PA, De Geest K, et al. Evaluation of new platinum-based treatment regimens in advanced-stage ovarian cancer: a Phase III Trial of the Gynecologic Cancer Intergroup. J Clin Oncol. 2009;27(9): 1419-25.

2. Colombo N, Sessa C, du Bois A, Ledermann J, McCluggage WG, McNeish Morice P, Pignata S, Ray-Coquard I, Vergote I, et al. ESMO-ESGO consensus conference recommendations on ovarian cancer: pathology and molecular biology, early and advanced stages, borderline tumours and recurrent diseasedagger. Annals Oncol. 2019:30(5):672-705.

3. De Angelis R, Sant M, Coleman MP, Francisci S, Baili P, Pierannunzio D, Trama A, Visser O, Brenner H, Ardanaz E, et al. Cancer survival in Europe 1999-2007 by country and age: results of EUROCARE--5-a population-based study. The Lancet Oncology. 2014;15(1):23-34.

4. du Bois A, Weber B, Rochon J, Meier W, Goupil A, Olbricht S, Barats JC, Kuhn W, Orfeuvre $H$, Wagner $U$, et al. Addition of epirubicin as a third drug to carboplatin-paclitaxel in first-line treatment of advanced ovarian cancer: a prospectively randomized gynecologic cancer intergroup trial by the Arbeitsgemeinschaft Gynaekologische Onkologie Ovarian Cancer Study Group and the Groupe d'Investigateurs Nationaux pour l'Etude des Cancers Ovariens. J Clin Oncol. 2006;24(7):1127-35.

5. Pfisterer J, Weber B, Reuss A, Kimmig R, du Bois A, Wagner U, Bourgeois H, Meier W, Costa S, Blohmer JU, et al. Randomized phase III trial of topotecan following carboplatin and paclitaxel in first-line treatment of advanced ovarian cancer: a gynecologic cancer intergroup trial of the AGO-OVAR and GINECO. Journal of the National Cancer Institute. 2006:98(15):1036-45.

6. Hoskins P, Vergote I, Cervantes A, Tu D, Stuart G, Zola P, Poveda A, Provencher D, Katsaros D, Ojeda B, et al. Advanced ovarian cancer: phase III randomized study of sequential cisplatin-topotecan and carboplatinpaclitaxel vs carboplatin-paclitaxel. Journal of the National Cancer Institute. 2010;102(20):1547-56.
7. Perren TJ, Swart AM, Pfisterer J, Ledermann JA, Pujade-Lauraine E, Kristensen G, Carey MS, Beale P, Cervantes A, Kurzeder C, et al. A phase 3 trial of bevacizumab in ovarian cancer. The New England journal of medicine. 2011:365(26):2484-96.

8. Burger RA, Brady MF, Bookman MA, Fleming GF, Monk BJ, Huang H, Mannel RS, Homesley HD, Fowler J, Greer BE, et al. Incorporation of bevacizumab in the primary treatment of ovarian cancer. The New England journal of medicine. 2011;365(26):2473-83.

9. Hoeijmakers JH. Genome maintenance mechanisms for preventing cancer. Nature. 2001;411(6835):366-74

10. Mirza MR, Pignata S, Ledermann JA. Latest clinical evidence and further development of PARP inhibitors in ovarian cancer. Annals of oncology : official journal of the European Society for Medical Oncology. 2018;29(6): 1366-76.

11. O'Connor MJ. Targeting the DNA damage response in cancer. Molecular cell. 2015;60(4):547-60

12. Moore K, Colombo N, Scambia G, Kim BG, Oaknin A, Friedlander M, Lisyanskaya A, Floquet A, Leary A, Sonke GS, et al. Maintenance olaparib in patients with newly diagnosed advanced ovarian cancer. The New England journal of medicine. 2018;379(26):2495-505.

13. Ray-Coquard I, Pautier P, Pignata S, Pérol D, González-Martín A, Berger R Fujiwara K, Vergote I, Colombo N, Mäenpää J, et al. Olaparib plus bevacizumab as first-line maintenance in ovarian cancer. The New England journal of medicine. 2019;381(25):2416-28.

14. Coleman RL, Fleming GF, Brady MF, Swisher EM, Steffensen KD, Friedlander M, Okamoto A, Moore KN, Efrat Ben-Baruch N, Werner TL, et al. Veliparib with first-line chemotherapy and as maintenance therapy in ovarian cancer. The New England journal of medicine. 2019:381(25):2403-15.

15. Murai J, Huang SY, Das BB, Renaud A, Zhang Y, Doroshow JH, Ji J, Takeda S, Pommier Y. Trapping of PARP1 and PARP2 by clinical PARP inhibitors. Cancer Res. 2012;72(21):5588-99.

16. Konecny GE, Kristeleit RS. PARP inhibitors for BRCA1/2-mutated and sporadic ovarian cancer: current practice and future directions. British journal of cancer. 2016;115(10):1157-73.

17. Ashworth A, Lord CJ. Synthetic lethal therapies for cancer: what's next after PARP inhibitors? Nature reviews Clinical oncology. 2018;15(9):564-76.

18. Helleday T. The underlying mechanism for the PARP and BRCA synthetic lethality: clearing up the misunderstandings. Molecular oncology. 2011;5(4): 387-93.

19. Schoonen PM, Talens F, Stok C, Gogola E, Heijink AM, Bouwman P, Foijer F: Progression through mitosis promotes PARP inhibitor-induced cytotoxicity in homologous recombination-deficient cancer cells. 2017, 8:15981.

20. Gu L, Fu R, Chen P, Du N, Chen S, Mao D, Chen B, Mao F, Khadaroo PA, Jin Q. In terms of nutrition, the most suitable method for bariatric surgery: laparoscopic sleeve gastrectomy or Roux-en-Y gastric bypass? a systematic review and meta-analysis. Obesity surgery. 2020.

21. Gu L, Du N, Jin Q, Li S, Xie L, Mo J, Shen Z, Mao D, Ji J, Khadaroo PA, et al. Magnitude of benefit of the addition of poly ADP-ribose polymerase (PARP) inhibitors to therapy for malignant tumor: A meta-analysis. Critical reviews in oncology/hematology. 2020;147:102888.

22. Du N, Chen M, Shen Z, Li S, Chen P, Khadaroo PA, Mao D, Gu L. Comparison of quality of life and nutritional status of between Roux-en-Y and Billroth-I reconstruction after distal gastrectomy: a systematic review and meta-analysis. Nutr Cancer. 2019:1-9.

23. Gu L, Khadaroo PA, Su H, Kong L, Chen L, Wang X, Li X, Zhu H, Zhong X, Pan J, et al. The safety and tolerability of combined immune checkpoint inhibitors (anti-PD-1/PD-L1 plus anti-CTLA-4): a systematic review and metaanalysis. BMC cancer. 2019;19(1):559.

24. Kaye SB, Lubinski J, Matulonis U, Ang JE, Gourley C, Karlan BY, Amnon A, Bell-McGuinn KM, Chen LM, Friedlander M, et al. Phase II, open-label, randomized, multicenter study comparing the efficacy and safety of olaparib, a poly (ADP-ribose) polymerase inhibitor, and pegylated liposomal doxorubicin in patients with BRCA1 or BRCA2 mutations and recurrent ovarian cancer. J Clin Oncol. 2012:30(4):372-9.

25. Oza AM, Cibula D, Benzaquen AO, Poole C, Mathijssen RH, Sonke GS, Colombo N, Špaček J, Vuylsteke P, Hirte H, et al. Olaparib combined with chemotherapy for recurrent platinum-sensitive ovarian cancer: a randomised phase 2 trial. Lancet Oncol. 2015;16(1):87-97.

26. Ledermann JA, Harter P, Gourley C, Friedlander M, Vergote I, Rustin G, Scott C, Meier W, Shapira-Frommer R, Safra T, et al. Overall survival in patients with platinum-sensitive recurrent serous ovarian cancer receiving olaparib 
maintenance monotherapy: an updated analysis from a randomised, placebo-controlled, double-blind, phase 2 trial. The Lancet Oncology. 2016; 17(11):1579-89.

27. Pujade-Lauraine E, Ledermann JA, Selle F, Gebski V, Penson RT, Oza AM, Korach J, Huzarski T, Poveda A, Pignata S, et al. Olaparib tablets as maintenance therapy in patients with platinum-sensitive, relapsed ovarian cancer and a BRCA1/2 mutation (SOLO2/ENGOT-Ov21): a double-blind, randomised, placebo-controlled, phase 3 trial. The Lancet Oncology. 2017; 18(9):1274-84.

28. Coleman RL, Oza AM, Lorusso D, Aghajanian C, Oaknin A, Dean A, Colombo N, Weberpals JI, Clamp A, Scambia G, et al. Rucaparib maintenance treatment for recurrent ovarian carcinoma after response to platinum therapy (ARIEL3): a randomised, double-blind, placebo-controlled, phase 3 trial. Lancet (London, England). 2017;390(10106):1949-61.

29. Del Campo JM, Matulonis UA, Malander S, Provencher D, Mahner S, Follana P, Waters J, Berek JS, Woie K, Oza AM, et al. Niraparib maintenance therapy in patients with recurrent ovarian cancer after a partial response to the last platinum-based chemotherapy in the ENGOT-OV16/NOVA Trial. Journal of clinical oncology : official journal of the American Society of Clinical Oncology. 2019;37(32):2968-73.

30. González-Martín A, Pothuri B, Vergote I, DePont CR, Graybill W, Mirza MR, McCormick C, Lorusso D, Hoskins P, Freyer G, et al. Niraparib in patients with newly diagnosed advanced ovarian cancer. New England J Med. 2019; 381(25):2391-402.

31. Mateo J, Lord CJ, Serra V, Tutt A, Balmaña J, Castroviejo-Bermejo M, Cruz C, Oaknin A, Kaye SB, de Bono JS. A decade of clinical development of PARP inhibitors in perspective. Annals of oncology : official journal of the European Society for Medical Oncology. 2019;30(9):1437-47.

32. Farmer H, McCabe N, Lord CJ, Tutt AN, Johnson DA, Richardson TB, Santarosa M, Dillon KJ, Hickson I, Knights C, et al. Targeting the DNA repair defect in BRCA mutant cells as a therapeutic strategy. Nature. 2005; 434(7035):917-21.

33. Fong PC, Boss DS, Yap TA, Tutt A, Wu P, Mergui-Roelvink M, Mortimer $P$, Swaisland H, Lau A, O'Connor MJ, et al. Inhibition of poly(ADP-ribose) polymerase in tumors from BRCA mutation carriers. The New England journal of medicine. 2009;361(2):123-34

34. Yap TA, Sandhu SK, Workman P, de Bono JS. Envisioning the future of early anticancer drug development. Nature reviews Cancer. 2010;10(7):514-23.

35. Mirza MR, Monk BJ, Herrstedt J, Oza AM, Mahner S, Redondo A, Fabbro M, Ledermann JA, Lorusso D, Vergote I, et al. Niraparib maintenance therapy in platinum-sensitive, recurrent ovarian cancer. The New England journal of medicine. 2016;375(22):2154-64.

36. Swisher EM, Lin KK, Oza AM, Scott CL, Giordano H, Sun J, Konecny GE, Coleman RL, Tinker AV, O'Malley DM, et al. Rucaparib in relapsed, platinum-sensitive high-grade ovarian carcinoma (ARIEL2 Part 1): an international, multicentre, open-label, phase 2 trial. The Lancet Oncology. 2017;18(1):75-87.

37. Kim DS, Camacho CV, Nagari A, Malladi VS, Challa S, Kraus WL. Activation of PARP-1 by snoRNAs controls ribosome biogenesis and cell growth via the RNA helicase DDX21. Molecular cell. 2019;75(6):1270-1285.e1214.

38. Ledermann J, Harter P, Gourley C, Friedlander M, Vergote I, Rustin G, Scott CL, Meier W, Shapira-Frommer R, Safra T, et al. Olaparib maintenance therapy in patients with platinum-sensitive relapsed serous ovarian cancer: a preplanned retrospective analysis of outcomes by BRCA status in a randomised phase 2 trial. The Lancet Oncology. 2014;15(8):852-61.

39. Majdak EJ, Debniak J, Milczek T, Cornelisse CJ, Devilee P, Emerich J, Jassem J, De Bock GH. Prognostic impact of BRCA1 pathogenic and BRCA1/BRCA2 unclassified variant mutations in patients with ovarian carcinoma. Cancer. 2005;104(5):1004-12

40. Bryant HE, Schultz N, Thomas HD, Parker KM, Flower D, Lopez E, Kyle S, Meuth M, Curtin NJ, Helleday T. Specific killing of BRCA2-deficient tumours with inhibitors of poly(ADP-ribose) polymerase. Nature. 2005: 434(7035):913-7.

41. Ledermann JA. PARP inhibitors in ovarian cancer. Annals Oncol. 2016; 27(Suppl 1):i40-4.

42. Helleday T, Petermann E, Lundin C, Hodgson B, Sharma RA. DNA repair pathways as targets for cancer therapy. Nature reviews Cancer. 2008;8(3): 193-204.

43. Bitler BG, Watson ZL, Wheeler LJ, Behbakht K. PARP inhibitors: clinical utility and possibilities of overcoming resistance. Gynecologic oncology. 2017; 147(3):695-704.
44. Frizzell KM, Kraus WL. PARP inhibitors and the treatment of breast cancer: beyond BRCA1/2? Breast cancer research : BCR. 2009;11(6):111.

45. Boamah EK, Kotova E, Garabedian M, Jarnik M, Tulin AV. Poly(ADP-Ribose) polymerase 1 (PARP-1) regulates ribosomal biogenesis in Drosophila nucleoli. PLoS genetics. 2012;8(1):e1002442.

46. Guetg C, Scheifele F, Rosenthal F, Hottiger MO, Santoro R. Inheritance of silent rDNA chromatin is mediated by PARP1 via noncoding RNA. Molecular cell. 2012:45(6):790-800.

47. Farrés J, Llacuna L, Martin-Caballero J, Martínez C, Lozano JJ, Ampurdanés C, López-Contreras AJ, Florensa L, Navarro J, Ottina E, et al. PARP-2 sustains erythropoiesis in mice by limiting replicative stress in erythroid progenitors. Cell death and differentiation. 2015;22(7):1144-57.

48. Berek JS, Matulonis UA, Peen U, Ghatage P, Mahner S, Redondo A, Lesoin A, Colombo N, Vergote I, Rosengarten O, et al. Safety and dose modification for patients receiving niraparib. Annals of oncology : official journal of the European Society for Medical Oncology. 2018;29(8):1784-92.

49. Oza AM, Matulonis UA, Malander S, Hudgens S, Sehouli J, Del Campo JM, Berton-Rigaud D, Banerjee S, Scambia G, Berek JS, et al. Quality of life in patients with recurrent ovarian cancer treated with niraparib versus placebo (ENGOT-OV16/NOVA): results from a double-blind, phase 3, randomised controlled trial. The Lancet Oncology. 2018;19(8):1117-25.

50. Friedlander M, Gebski V, Gibbs E, Davies L, Bloomfield R, Hilpert F, Wenzel LB, Eek D, Rodrigues M, Clamp A, et al. Health-related quality of life and patient-centred outcomes with olaparib maintenance after chemotherapy in patients with platinum-sensitive, relapsed ovarian cancer and a BRCA1/2 mutation (SOLO2/ENGOT Ov-21): a placebo-controlled, phase 3 randomised trial. The Lancet Oncology. 2018;19(8):1126-34.

51. LaFargue CJ, Dal Molin GZ, Sood AK, Coleman RL. Exploring and comparing adverse events between PARP inhibitors. Lancet Oncol. 2019;20(1):e15-28.

\section{Publisher's Note}

Springer Nature remains neutral with regard to jurisdictional claims in published maps and institutional affiliations.
Ready to submit your research? Choose BMC and benefit from:

- fast, convenient online submission

- thorough peer review by experienced researchers in your field

- rapid publication on acceptance

- support for research data, including large and complex data types

- gold Open Access which fosters wider collaboration and increased citations

- maximum visibility for your research: over $100 \mathrm{M}$ website views per year

At BMC, research is always in progress.

Learn more biomedcentral.com/submissions 